\title{
Evaluation of reproductive barriers contributes to the development of novel interspecific hybrids in the Kalanchoë genus
}

\author{
Katarzyna Kuligowska ${ }^{*}$, Henrik Lütken ${ }^{1}$, Brian Christensen², lb Skovgaard ${ }^{3}$, Marcus Linde ${ }^{4}$, Traud Winkelmann ${ }^{5}$
} and Renate Müller ${ }^{1}$

\begin{abstract}
Background: Interspecific hybridization is a useful tool in ornamental breeding to increase genetic variability and introduce new valuable traits into existing cultivars. The successful formation of interspecific hybrids is frequently limited by the presence of pre- and post-fertilization barriers. In the present study, we investigated the nature of hybridization barriers occurring in crosses between Kalanchoë species and evaluated possibilities of obtaining interspecific hybrids.

Results: The qualitative and quantitative analyses of pollen tube growth in situ were performed following intra- and interspecific pollinations. They revealed occurrence of pre-fertilization barriers associated with inhibition of pollen germination on the stigma and abnormal growth of pollen tubes. Unilateral incongruity related to differences in pistil length was also observed. The pollen quality was identified as a strong factor influencing the number of pollen tubes germinating in the stigma. In relation to post-fertilization barriers, endosperm degeneration was a probable barrier hampering production of interspecific hybrids. Moreover, our results demonstrate the relation of genetic distance estimated by AFLP marker analysis of hybridization partners with cross-compatibility of Kalanchoë species. At the same time, differences in ploidy did not influence the success of interspecific crosses.

Conclusions: Our study presents the first comprehensive analysis of hybridization barriers occurring within Kalanchoë genus. Reproductive barriers were detected on both, pre- and post-fertilization levels. This new knowledge will contribute to further understanding of reproductive isolation of Kalanchoë species and facilitate breeding of new cultivars. For the first time, interspecific hybrids between K. nyikae as maternal plant and K. blossfeldiana as well as $K$. blossfeldiana and K. marnieriana were generated.
\end{abstract}

Keywords: AFLP markers, Chromosome number, Cross-compatibility, Endosperm development, Genetic distance, Pollen tube growth, Pre-zygotic barrier, Post-zygotic barrier

\section{Background}

Interspecific hybridization, as a mean to increase genetic variability and introduce new valuable traits, has been carried out in many cultivated plants. In the field of ornamental breeding, interspecific hybridization is considered to be one of the most useful strategies to develop new cultivars. This technique has been successfully used as a breeding tool in ornamental plants including Rosa [1],

\footnotetext{
* Correspondence: kku@plen.ku.dk

'Department of Plant and Environmental Sciences, Faculty of Science, University of Copenhagen, Højbakkegård Allé 9-13, DK-2630 Taastrup, Denmark

Full list of author information is available at the end of the article
}

Chrysanthemum [2], Dianthus [3], Lilium [4] and Rhododendron [5].

Crosses among plants belonging to different species are naturally occurring phenomena when distributions of species overlap [6]. There are, however, processes that ensure reproductive isolation of distinct species. Hybridization barriers that hamper the development of interspecific hybrids are typically recognized as pre-fertilization barriers and post-fertilization barriers, depending on the time point of their action during the hybridization process. Prefertilization barriers prevent mating and fertilization. They include lack of stigma receptivity or pollen viability at the 
time of pollination or abnormal growth of pollen tubes in the style and ovary of recipient partner [7]. Successful formation of hybrid plants may also be limited by postfertilization barriers. They include embryo and endosperm abortion, abnormal growth and unviability of hybrids or their sterility [7].

The Kalanchoë genus belongs to the Crassulaceae family and consists of around 140 species, mostly succulents. Kalanchoë species are mainly native to Madagascar and the east coast of Africa. The genus is divided into two sections Kalanchoë and Bryophyllum, based primarily on flower characteristics and an ability to viviparous plant formation [8]. The first plant of Kalanchoë blossfeldiana was introduced to Europe from Madagascar in 1924. Development of new cultivars was initiated in 1930's, however, it resulted from selection within the progeny of a single plant. Interspecific hybridization of $K$. blossfeldiana was successfully conducted in 1939, when the first interspecific hybrid with K. flammea was obtained. From the beginning, breeding of Kalanchoë cultivars was focused on compactness and flower characteristics such as color and double flowers [9]. Thus, little variation is present in respect to other plant features.

K. blossfeldiana and its interspecific hybrids are popular ornamental plants. They are used both as flowering potted plants and garden plants. Kalanchoë cultivars are economically important with an annual production of 41 million plants in Denmark in 2012 [10]. In the Netherlands, 77 million plants were produced with turnover of 55 million euros in 2012 [11].

Within the Kalanchoë genus, there are other species with various interesting features like different plant architecture, flower shape or leaf morphology. Thus, wild species within the Kalanchoë genus represent essential genetic resources that may increase the restricted genetic basis of modern $K$. blossfeldiana cultivars.

There have been previous reports on interspecific hybridization in the Kalanchoë genus. Intrasectional hybridization resulted in hybrid progeny among $K$. blossfeldiana and several other Kalanchoë species such as $K$. citrina, K. farinacea, K. garambiensis, K. nyikae, K. pumila, K. spathulata [12]. Successful intersectional hybridization was previously reported among $K$. blossfeldiana and $K$. daigremontiana, K. laxiflora, $K$. pubescens, as well as $K$. spathulata and K. laxiflora [13]. However, a systematic investigation of general crosscompatibility among Kalanchoë species is missing and the nature of hybridization barriers occurring during hybridization is unknown. Information about chromosome numbers in the genus is also limited.

The objectives of this study were to identify the nature of hybridization barriers occurring in reciprocal crosses among selected Kalanchoë species. The influence of plant genotype, chromosome numbers determined by
DAPI staining and genetic similarity assessed by AFLP markers on cross-compatibility and production of novel interspecific hybrids within the Kalanchoë genus was evaluated. The analysis of interspecific crosses revealed the hybridization barriers during both, the pre- and post-fertilization phase of reproductive process. They were related to parental divergence and influenced by the specific genetic background of parental plants. The obtained interspecific progeny exhibited intermediate phenotypes typical for hybrids. In addition, transgressive segregation was also observed in some of the hybrid lines.

\section{Methods}

\section{Plant material}

Seven genotypes belonging to six Kalanchoë species were used in the experiment; two cultivars of $K$. blossfeldiana VAN POELLN. 'Jackie' and '0089A' and five wild species: K. nyikae BAK., K. pubescens BAK., K. marnieriana JACOBS., $K$. campanulata (BAK.) BAILL., K. gracilipes (BAK.) BAILL. The taxonomic position and origin of the species are shown in Table 1. Leaf and flower morphologies are presented in Figure 1A.

Plants were established from cuttings obtained from the greenhouse nursery Knud Jepsen A/S, Hinnerup, Denmark. The plants were cultivated in the greenhouse from April 2011 until April 2013 under standard conditions $\left(22 / 18 \pm 4^{\circ} \mathrm{C}\right.$ day/night) and irrigated every second day with standard fertilizer (Pioner NPK Makro 14-3-23). Plants were kept under long day conditions with a photoperiod of $16 / 8 \mathrm{~h}$, day/night with additional light of $260 \mu \mathrm{mol} \mathrm{s}^{-1} \mathrm{~m}^{-2}$ (Philips Master SON-T PIA Green Power $400 \mathrm{~W})$. For flower induction plants were transferred to short day conditions $(8 / 16 \mathrm{~h}$, day/night) for about 10 weeks.

\section{Determination of chromosome number}

For cytological observations the shoot tips with three leaf pairs were excised from parental plants and rooted in hydroponics for approx. 2 weeks. The root tips of induced adventitious roots were collected and prepared according to Lütken et al. [14]. DAPI-stained chromosomes were

\section{Table 1 Overview of parental plants}

\begin{tabular}{lll}
\hline Species & Section & Origin \\
\hline K. blossfeldiana VAN POELLN. cv. '0089A' & Kalanchoë & Madagascar \\
K. blossfeldiana hybrid cv. 'Jackie' & & \\
K. nyikae BAK. & Kalanchoë & Africa \\
K. pubescens BAK. & Bryophyllum & Madagascar \\
K. marnieriana JACOBS. & Bryophyllum & Madagascar \\
K. campanulata (BAK.) BAILL. & Bryophyllum & Madagascar \\
K. gracilipes (BAK.) BAILL. & Bryophyllum & Madagascar \\
\hline
\end{tabular}




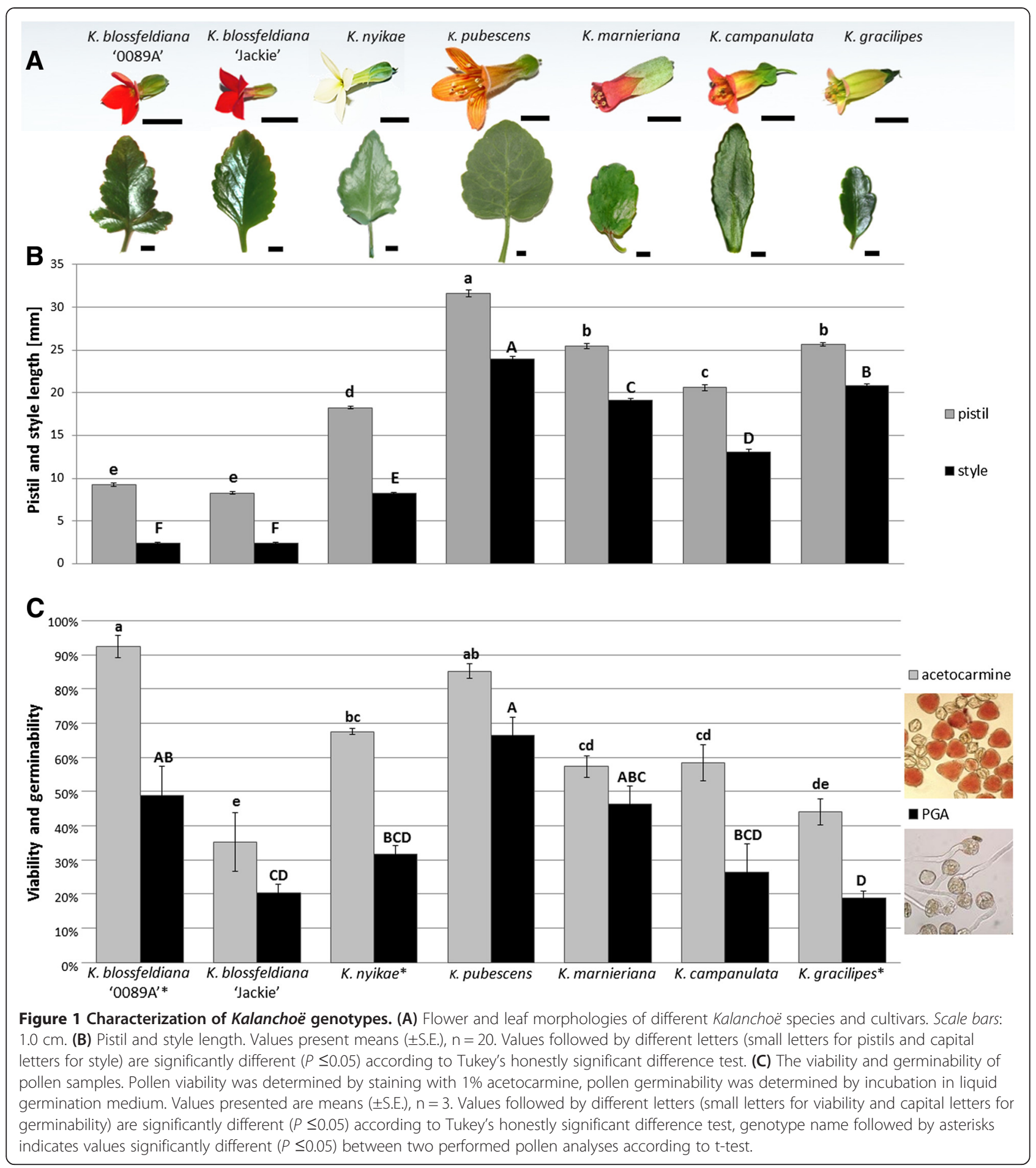

examined under the fluorescence microscope (Motic BA410, Wetzlar, Germany; excitation filter BP $350 \mathrm{~nm}$ ) equipped with a digital camera (Moticam Pro 252, Wetzlar, Germany). A minimum of five cells with clearly visible chromosomes was observed for each genotype from at least two different plants.

\section{DNA extraction and AFLP analysis}

Approximately $2 \mathrm{~g}$ of fresh leaf or flower material was immersed in liquid nitrogen and ground into a fine powder. Total genomic DNA was extracted from plants following the CTAB method after Doyle and Doyle [15]. Approx. $10 \mathrm{ml}$ of CTAB extraction buffer $(100 \mathrm{mM}$ 
Tris- $\mathrm{HCl} \mathrm{pH}$ 8.0, 2\% (w/v) CTAB, $20 \mathrm{mM} \mathrm{Na}{ }_{2}$ EDTA, 1.4 $\mathrm{M} \mathrm{NaCl}, 3 \%(\mathrm{w} / \mathrm{v})$ PVPP and $1 \%(\mathrm{v} / \mathrm{v}) \quad \beta-$ mercaptoethanol) and RNase A (10U) were added. Samples were incubated for $1 \mathrm{~h}$ at $65^{\circ} \mathrm{C}$ with occasional shaking. Afterwards, samples were homogenized with 1 vol. of chloroform:isoamyl alcohol (24:1) for $20 \mathrm{~min}$ and centrifuged for $25 \mathrm{~min}$ at $4250 \times \mathrm{g}$. The supernatant was transferred to a new tube and chloroform:isoamyl alcohol extraction was repeated. Subsequently, 1 vol. of ice-cold isopropanol was added to the supernatant and samples were left for DNA precipitation overnight at $-20^{\circ} \mathrm{C}$. On the next day, samples were centrifuged for $5 \mathrm{~min}$ at $4250 \times \mathrm{g}$ and the pellet was washed with $96 \%$ $\mathrm{v} / \mathrm{v}$ and $70 \% \mathrm{v} / \mathrm{v}$ ethanol and dried. DNA was dissolved in $\mathrm{dd}_{2} \mathrm{O}$. DNA concentration and quality was estimated in comparison to known DNA concentrations of $\lambda$-DNA in a $1 \%$ agarose gel following electrophoresis.

The AFLP method was performed essentially as described by Vos et al. [16] with minor modifications. The genomic DNA (100 ng) was digested with the restriction enzymes HindIII (9 U) and MseI (3.6 U) overnight at $37^{\circ} \mathrm{C}$. The HindIII adapter (5'AGCTGGTACGCAGTCTAC) $(2.5 \mathrm{pmol})$ and $\mathrm{Mse}$ I adapter (5'-ACTCAGGACTCAT) (25 pmol) were ligated to the restriction fragments with $0.25 \mathrm{U}$ of T4-DNA ligase at $37^{\circ} \mathrm{C}$ for $3.5 \mathrm{~h}$. For the pre-amplification, primers homologues to the adapter and the restriction site sequences containing one selective nucleotide (HindIII) or no selective nucleotide (MseI) were used. Selective amplification was carried out using Hin$d \mathrm{III} /$ MseI with three selective nucleotides at the 3 '-end. The 5'-end of the HindIII primer was IRD700 labeled. To estimate the reproducibility of the AFLP marker pattern, two independent analyses starting from the restriction until the selective amplification were performed for the three genotypes $K$. blossfeldiana '0089A', K. pubescens and $K$. gracilipes. No deviating banding patterns were observed between the two replicates using -AAC/-CCA (HindIII/ MseI) primer combinations.

All AFLP reactions for the estimation of the genetic diversity and the hybrid identification were performed on samples from two independent DNA extractions per genotype. The PCR fragments were separated using $6 \%$ denaturing polyacrylamide gels under standard conditions. The gels were scanned with an automatic LI-COR DNA sequencer (LI-COR Global IR2 4200LI-1 Sequencing System, LI-COR) for fragment detection. Only reproducible bands for the two independent biological replicates of each genotype were included in the further analysis.

\section{Analysis of genetic diversity}

The banding patterns were assessed by visual inspection and transformed into a 0/1 matrix for each DNA fragment. Genetic distances were calculated using the FAMD
1.3 software package (http://www.famd.me.uk/famd.html). The pairwise distances between the analyzed plants were calculated using Jaccard similarity index. A cluster analysis was performed using the Neighbour-Joining method (Saitou and Nei 1987) [17]. To evaluate the robustness of the dendrogram, a bootstrap analysis (Felsenstein 1985) [18] with 1000 replicates was conducted. The dendrogram was constructed using FAMD (Schlüter and Harris 2006) [19] and displayed using Mega 5.2.2 (http://www.megasoftware.net/).

\section{Sexual hybridizations}

Intraspecific and interspecific crosses were performed on a total of 29 cross-combinations (7 self-pollinations, 2 intraspecific - crosses of the two $K$. blossfeldiana genotypes and 20 interspecific crosses, Table 2). Pollination was carried out from April 2012 to April 2013. Interspecific crosses included reciprocal pollination between each of the two cultivars of $K$. blossfeldiana and the five other species within the Kalanchoë genus.

Flowers of the Kalanchoë species were emasculated in the bud stage, 3 to 1 day prior to anthesis. Anthers (and a part of corolla in $K$. blossfeldiana and $K$. nyikae) were removed using forceps. Flowers were pollinated in the expanded sticky stage of stigma with fresh pollen using a brush. Pollinated flowers were used either for examination of pollen tube growth in situ or left for the seed to mature for later collection.

\section{Pollen quality \\ Pollen viability}

Pollen was collected at the point of anther dehiscence i.e. the day of flower opening before noon. Pollen of 10 flowers was immersed in a drop of $1 \%(\mathrm{w} / \mathrm{v})$ acetocarmine solution [20]. Pollen was examined under the light microscope (Leitz DMRD, Leica, Germany) and pollen grains were scored: stained red as viable and unstained as unviable.

\section{In vitro pollen germination}

The assessment of germinability in vitro was conducted in liquid medium after Taylor [21]: 0.04\% (w/v) $\mathrm{H}_{3} \mathrm{BO}_{3}$, $0.04 \%$ (w/v) $\mathrm{Ca}\left(\mathrm{NO}_{3}\right)_{2}, 0.07 \%$ (w/v) $\mathrm{MnSO}_{4}$ with $10 \% \mathrm{su}-$ crose concentration. The selection of culture medium was made following a preliminary screening (data not shown). Pollen of 10 flowers were immersed in this medium on glass slides and covered with cover glass. After $2 \mathrm{~h}$ of incubation (dark, room temperature) pollen grains were analyzed by the light microscope (Leitz DMRD, Leica, Germany). Pollen grains were classified as able to germinate when the pollen tube length exceeded the diameter of the pollen grain. 
Table 2 Overview of intra- and interspecific crosses among Kalanchoë species

\begin{tabular}{|c|c|c|c|c|c|c|c|c|c|c|c|}
\hline \multicolumn{2}{|l|}{ Genetic distance } & 우 & $\pi$ & $\begin{array}{l}\text { No. of } \\
\text { flowers } \\
\text { pollinated }\end{array}$ & $\begin{array}{l}\text { Mean no. of } \\
\text { seeds per } \\
\text { capsule (SE) }\end{array}$ & $\begin{array}{l}\text { Germination } \\
\text { percentage }^{b}\end{array}$ & $\begin{array}{l}\text { Total no. of } \\
\text { seedlings }\end{array}$ & $\begin{array}{l}\text { Total no. } \\
\text { of plants }\end{array}$ & $\begin{array}{l}\text { Seedling } \\
\text { survival [\%] }\end{array}$ & $\begin{array}{l}\text { Total no. } \\
\text { of hybrids }\end{array}$ & Hybrids [\%] \\
\hline \multirow{7}{*}{\multicolumn{2}{|c|}{ Self-pollination }} & K. $b^{1}{ }^{\prime} 0089 A^{\prime}$ & K. b. '0089A' & 10 & $40.8(8.4)$ & 52 & 418 & 400 & 96 & $N A^{e}$ & NA \\
\hline & & K. b. 'Jackie' & K. b. 'Jackie' & 10 & $5.0(1.6)$ & 40 & 3 & 3 & 100 & NA & NA \\
\hline & & K. nyikae & K. nyikae & 10 & $>50.0$ & 67 & 1520 & $249^{d}$ & 83 & NA & NA \\
\hline & & K. pub. ${ }^{2}$ & K. pub. & 10 & $>50.0$ & 98 & 398 & 390 & 98 & NA & NA \\
\hline & & K. mar. ${ }^{3}$ & K. mar. & 10 & $>50.0$ & 63 & 369 & 254 & 69 & NA & NA \\
\hline & & K. cam. ${ }^{4}$ & K. cam. & 10 & $12.2(3.8)$ & 98 & 71 & 71 & 100 & NA & NA \\
\hline & & K. gra. $^{5}$ & K. gra. & 10 & 0.0 & $-^{c}$ & 0 & - & - & - & - \\
\hline \multirow[t]{2}{*}{ Intra-specific } & 0.312 & K. b. '0089A' & K. b. 'Jackie' & 10 & $28.0(6.3)$ & 93 & 328 & 320 & 98 & $N D^{f}$ & ND \\
\hline & & K. b. 'Jackie' & K. b. '0089A' & 10 & $11.8(3.2)$ & 63 & 62 & 60 & 97 & ND & ND \\
\hline \multirow[t]{4}{*}{ Intra-sectional } & 0.695 & K. b. '0089A' & K. nyikae & 84 & $28.2(4.7)$ & 87 & 1521 & $213^{d}$ & 71 & 213 & 100.0 \\
\hline & & K. nyikae & K. b. '0089A' & 36 & $4.3(1.0)$ & 88 & 167 & 131 & 78 & 11 & 9.2 \\
\hline & 0.695 & K. b. 'Jackie' & K. nyikae & 42 & $6.0(1.7)$ & 88 & 234 & 121 & 52 & 121 & 100.0 \\
\hline & & K. nyikae & K. b. 'Jackie' & 60 & $0.2(0.1)$ & - & 0 & - & - & - & - \\
\hline \multirow[t]{16}{*}{ Inter-sectional } & 0.73 & K. b. '0089A' & K. pub. & 95 & $2.9(0.9)$ & 65 & 149 & 73 & 49 & 73 & 100.0 \\
\hline & & K. pub. & K. b. '0089A' & 94 & 0.0 & - & 0 & - & - & - & - \\
\hline & 0.77 & K. b. '0089A' & K. cam. & 136 & 0.0 & - & 0 & - & - & - & - \\
\hline & & K. cam. & K. b. '0089A' & 77 & 0.0 & - & 0 & - & - & - & - \\
\hline & 0.781 & K. b. '0089A' & K. mar. & 76 & $2.5(1.0)$ & 37 & 94 & 89 & 95 & 23 & 25.8 \\
\hline & & K. mar. & K. b. '0089A' & 54 & 0.0 & - & 0 & - & - & - & - \\
\hline & 0.785 & K. b. '0089A' & K. gra. & 122 & 0.0 & - & 0 & - & - & - & - \\
\hline & & K. gra. & K. b. '0089A' & 110 & 0.0 & - & 0 & - & - & - & - \\
\hline & 0.733 & K. b. 'Jackie' & K. pub. & 101 & $1.3(0.4)$ & 67 & 94 & 46 & 49 & 46 & 100.0 \\
\hline & & K. pub. & K. b. 'Jackie' & 44 & 0.0 & - & 0 & - & - & - & - \\
\hline & 0.764 & K. b. 'Jackie' & K. cam. & 160 & 0.0 & - & 0 & - & - & - & - \\
\hline & & K. cam. & K. b. 'Jackie' & 60 & 0.0 & - & 0 & - & - & - & - \\
\hline & 0.783 & K. b. 'Jackie' & K. gra. & 92 & 0.0 & - & 0 & - & - & - & - \\
\hline & & K. gra. & K. b. 'Jackie' & 51 & 0.0 & - & 0 & - & - & - & - \\
\hline & 0.801 & K. b. 'Jackie' & K. mar. & 68 & $0.2(0.2)$ & - & 0 & - & - & - & - \\
\hline & & K. mar. & K. b. 'Jackie' & 112 & 0.0 & - & 0 & - & - & - & - \\
\hline
\end{tabular}

${ }^{a} \mathrm{n}=10 ;{ }^{b} \mathrm{n}=60$; ${ }^{\mathrm{C}}$ not applicable; ${ }^{\mathrm{d}}$ out of 300 transferred seedlings; ${ }^{\mathrm{e}}$ not applicable; ${ }^{\mathrm{f}}$ no data available.

${ }^{1}$ K. b. - K. blossfeldiana; ${ }^{2}$ K. pub. - K. pubescens; ${ }^{3}$ K. mar. - K. marnieriana; ${ }^{4}$ K. cam. - K. campanulata; ${ }^{5}$ K. gra. - K. gracilipes.

The table presents seed production, germination and hybrid production of intraspecific crosses and interspecific crosses of two $K$. blossfeldiana cultivars that are ordered according to genetic distance. 
At least 100 pollen grains were analyzed per species. Each experiment was performed once in three technical replicates.

\section{Pollen tube growth in situ}

Pollen tube growth was examined for all interspecific and intraspecific crosses at two time points: 24 and 48 hours after pollination. For each time point, carpels of 10 flowers were harvested and fixed in a 3:1 solution of absolute ethanol and glacial acetic acid. After $24 \mathrm{~h}$ the pistils were transferred to $70 \%(\mathrm{v} / \mathrm{v})$ ethanol and stored at $4^{\circ} \mathrm{C}$ until use. Pistils were softened in $1 \mathrm{M} \mathrm{NaOH}$ for 25-35 min at $55^{\circ} \mathrm{C}$ and stained overnight with $0.1 \%(\mathrm{w} / \mathrm{v})$ aniline blue in $50 \mathrm{mM} \mathrm{KPO}_{4}$ buffer in the dark. Subsequently, pistils were placed in $40 \%(\mathrm{v} / \mathrm{v})$ glycerol and squashed under cover glass. Microscopic slides were stored at $4^{\circ}$ until examination. Pollen tubes were examined under the fluorescent microscope (Leitz DMRD, Leica, Germany; excitation filter BP 340-360 nm) equipped with a digital camera (Leica DFC420, Leica, Germany).

Since the size of the pistil differed significantly among the species, pollen tube growth was evaluated at three positions: 1- pollen grains germinated on stigma, 2pollen tubes visible at half the length of the style, 3pollen tubes in the ovary reaching ovules (Figure 2). The number of pollen grains/pollen tubes was quantified for each position according to the criteria: 0- no germinated pollen grains/tubes 1 - up to 10 germinated pollen grains/tubes, 2- several germinated pollen grains/tubes 3- dozens to hundreds germinated pollen grains/tubes.

\section{Seed morphology, germination and plant production}

Seeds were collected at maturity 30-60 days after pollination depending on the seed parent. The obtained seeds were evaluated regarding their morphology under the stereomicroscope (Leitz DMRD, Leica, Germany). To determine germination percentage, 60 seeds were placed in transparent plastic germination boxes $(12 \times 8 \times 5 \mathrm{~cm}$, $\mathrm{L} \times \mathrm{W} \times \mathrm{H}$ ) on moist filter paper (grade: $3 \mathrm{~W}$, Munktell Filter AB, Grycksbo, Sweden). The remaining harvested seeds were sown in peat (Pindstrup Substrate no. 1, Pindstrup Mosebrug A/S). Seedling survival was determined one month after sowing. Plants were then transplanted and grown in $11 \mathrm{~cm}$ pots with peat in the greenhouse $\left(22 / 18 \pm 4^{\circ} \mathrm{C}\right.$ day/night). Plants were kept under long day conditions $(16 / 8 \mathrm{~h}$, day/night). Mean number of seeds per capsule, germination percentage, number of seedlings obtained, seedling survival and number of plants and hybrids were recorded.

\section{Statistical analysis of phenotypic traits}

The morphological evaluation of parental plants and pollen quality: the significance of differences was

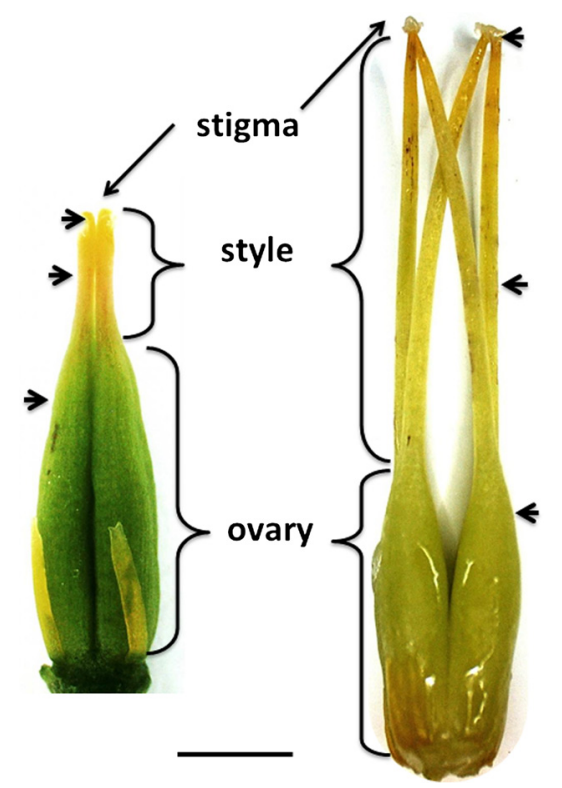

Figure $\mathbf{2}$ The morphology of pistils. Arrows indicate places in which pollen tubes were examined. Scale bar: $2.0 \mathrm{~mm}$.

determined using one-way analysis of variance followed by Tukey's honestly significant difference test (HSD) in the SPSS 22.0 for Windows statistical software package (SPSS Inc., Chicago, IL, USA).

For the analysis of pollen tube growth in situ, each of the five wild species used as maternal plants, the three paternal species (the two $K$. blossfeldiana cultivars and self-pollination of maternal plants) were compared in a one-way analysis of variance (ANOVA) for each time point $(24 \mathrm{~h}, 48 \mathrm{~h}$ ) followed by a pairwise comparison by a t-test. The same analysis was performed for reciprocal crosses, i.e. when five wild species and the two K. blossfeldiana cultivars were used as paternal plants, thus comparing the different maternal plants. All these analyses used $\mathrm{R}$ software version 3.0.3.

Simple and multiple linear regressions were used to relate the viability, germinability and genetic distance to the numbers of pollen tubes obtained after interspecific pollinations using $\mathrm{R}$ software version 3.0.3. Also this analysis was carried out for the two time points separately, with the 29 means, one from each cross, used as response variables.

\section{Results}

\section{Morphological evaluation of parent plants}

Pistil and style length were measured in the period of stigma receptivity, since the styles of the species from the Bryophyllum section elongate during flower maturation. Both carpels and style lengths were significantly different $(P \leq 0.05)$ between the species with much longer carpels and styles in the species of the Bryophyllum 
section (Figure 1B). No significant differences were observed between the two cultivars of $K$. blossfeldiana. The lengths of the pistil and style were the highest for $K$. pubescens i.e. $31.6 \mathrm{~mm} \pm 0.4 \mathrm{~mm}$ (mean and S.E.) and $24.0 \mathrm{~mm} \pm 0.3 \mathrm{~mm}$, respectively. The shortest pistil was observed for $K$. blossfeldiana 'Jackie' i.e. $8.3 \mathrm{~mm} \pm$ $0.1 \mathrm{~mm}$, whereas the shortest style was observed for $K$. blossfeldiana '0089A' i.e. $2.4 \mathrm{~mm} \pm 0.1 \mathrm{~mm}$.

\section{Cytological analysis}

Chromosomes were counted for all species used in the hybridization. Both cultivars of $K$. blossfeldiana were found to be tetraploid with $2 n=68$. The other species exhibited chromosome numbers typical for the Kalanchoë genus of $2 \mathrm{n}=34$ ( $K$. pubescens, $K$. marnieriana and $K$. gracilipes) and $2 \mathrm{n}=68$ ( $K$. nyikae and $K$. campanulata). During examination also single cells with higher ploidy levels were observed that can be explained by the polysomic nature of Kalanchoë species [12].

\section{Genetic diversity of the parental Kalanchoë genotypes}

To evaluate the genetic relations among genotypes and species used in interspecific crosses, the seven genotypes were analyzed using 10 AFLP primer combinations. The number of scored marker fragments per primer pair is shown in Additional file 1. In total 856 marker fragments were produced for the Kalanchoë species and Cotyledon tomentosa as outgroup. The genetic distance between the two K. blossfeldiana cultivars was 0.312 . The minimal genetic distance between two species was 0.695 for both $K$. blossfeldiana cultivars and K. nyikae, whereas the maximal genetic distance observed for $K$. blossfeldiana 'Jackie' and K. marnieriana was 0.801 (Table 2).
Based on the Jaccard similarity indexes a phenogram was calculated using the Neighbor-joining method. The phenogram differentiated two major clades representing the two sections of the Kalanchoë genus, Kalanchoë and Bryophyllum (Figure 3). The two species, K. marnieriana and $K$. gracilipes, previously classified to the separate Kitchinga section [22], grouped into a subcluster within the Bryophyllum section.

\section{Pollen quality}

Pollen analyses were carried out to investigate if pollen quality was a limiting factor in the hybridization process. The level of pollen viability and germination ability differed significantly among the species. The highest level of pollen viability was observed for $K$. blossfeldiana '0089A' i.e. $92 \% \pm 3 \%$ (mean and S.E.), whereas the lowest level of pollen viability was detected for $K$. blossfeldiana 'Jackie' $35 \% \pm 9 \%$. The highest level of pollen germinability was observed for $K$. pubescens i.e. $67 \% \pm$ $5 \%$. K. gracilipes exhibited the lowest level of pollen germinability i.e. $19 \% \pm 2 \%$. The results of the two methods differed significantly for three genotypes: $K$. blossfeldiana '0089A', K. nyikae and K. gracilipes. Thus, the data demonstrate that not all pollen grains, which were viable according to the staining test, were able to germinate (Figure 1C).

\section{Pollen tube growth}

Pollen tube growth was examined in carpels following the intra- and interspecific crosses sampled $24 \mathrm{~h}$ and $48 \mathrm{~h}$ after pollination. Already after $24 \mathrm{~h}$ pollen tubes were detected in the ovary of all Kalanchoë species, thus the theoretical time of fertilization was determined to be less than $24 \mathrm{~h}$.

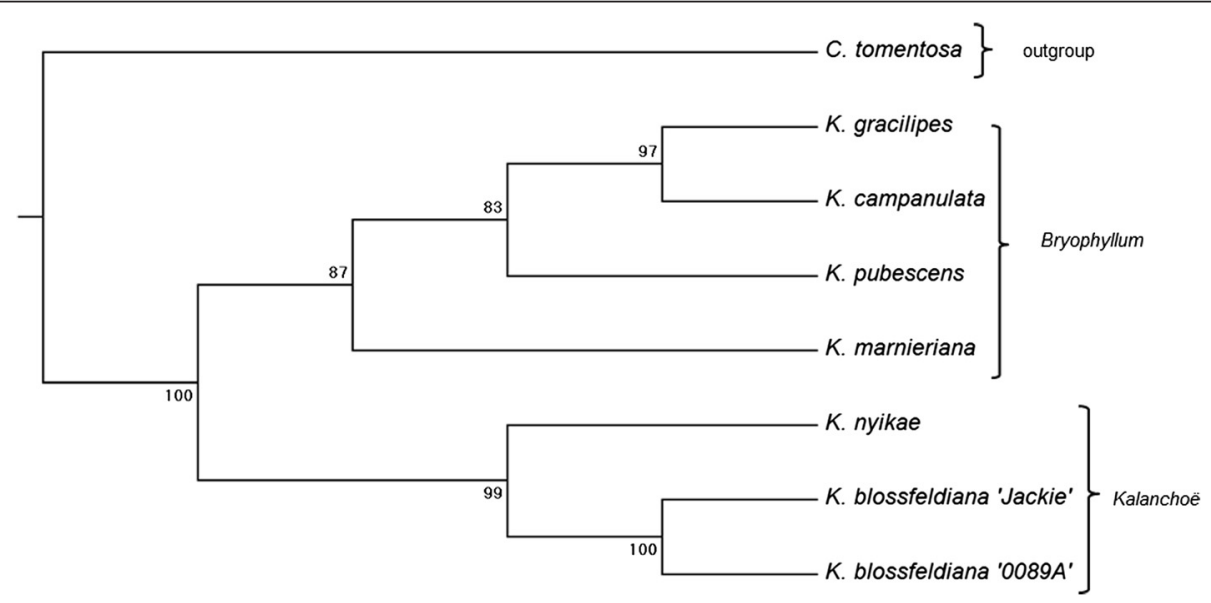

Figure 3 Genetic relatedness of parental plants. Neighbor-joining phenogram based on Jaccard similarity indexes computed from 856 AFLP markers for 7 Kalanchoë species and genotypes and Cotyledon tomentosa as the outgroup. The two sections of Kalanchoë genus: Kalanchoë and Bryophyllum are noted. The bootstrap percentages are shown next to the branches. 
The analysis of the numbers of pollen tubes presented similar patterns for $24 \mathrm{~h}$ and $48 \mathrm{~h}$. Only in selfpollinations of $K$. pubescens a significant increase in the number of pollen tubes was detected in the ovaries $48 \mathrm{~h}$ after pollination compared with $24 \mathrm{~h}$ (Additional file 2, Figure 4).

In the carpels sampled $48 \mathrm{~h}$ after self-pollinations, high numbers of pollen tubes were detected in the ovaries (Figure 4, green bars). The only exceptions were observed for $K$. blossfeldiana 'Jackie' and K. gracilipes, where numbers of pollen tubes were lower.

When $K$. blossfeldiana cultivars were used as maternal plants, the levels of pollen tubes in stigmas, styles and ovaries exhibited the same pattern (Figure $4 \mathrm{~A}, \mathrm{~B}$ and $\mathrm{C}$ ). Whereas, the reciprocal crosses (Figure 4D,E and F) showed decreased numbers of pollen tubes in the style (cross with $K$. pubescens: compare Figure 4B and E $K$. pub.). Even more dramatic decline of pollen tube numbers was observed in the ovaries following all inter-sectional crosses (Figure 4F).

The numbers of pollen tubes observed in crosses with $K$. blossfeldiana generally showed higher values when using $K$. blossfeldiana '0089A' as a pollen donor (Figure 4D-F, blue vs red bars). However, in the crosses where $K$. marnieriana and $K$. campanulata were used as maternal plants, pollinations with $K$. blossfeldiana 'Jackie' resulted in significantly higher numbers of pollen tubes in the ovaries (Figure 4F).

Qualitative analysis following intraspecific crosses revealed no abnormalities in pollen tube growth for the majority of the examined flowers (data not shown). An abnormal development was only detected in self-pollinations of $K$. blossfeldiana 'Jackie' and in the cross between $K$. blossfeldiana 'Jackie' and K. blossfeldiana '0089A'. Analysis of pollen tube growth following interspecific hybridization revealed different types of abnormalities that occurred in all examined cross-combinations. They included branching of the pollen tube (Figure 5B), spiky pollen tubes (Figure 5D), swelling of the tip (Figure $5 \mathrm{E}$ ) and disorientation of pollen tubes.

Microscopic analysis also revealed that penetration of ovules by the pollen tubes occurred for all crosscombinations when $K$. blossfeldiana '0089A' was used as maternal plant (Figure 5F-I). For K. blossfeldiana 'Jackie' ovule penetration was observed in crosses with $K$. nyikae, $K$. pubescens and $K$. marnieriana, and pollen tubes next to the ovules in other cross-combinations. When $K$. blossfeldiana plants were used as pollen donor, penetration of ovules was observed only in crosses with K. nyikae. In general, the observation of ovule penetration by pollen tubes suggests that fertilization takes place.

\section{Correlation analyses}

The regression analysis of pollen tubes observed after 48 $\mathrm{h}$ showed significant correlation between numbers of pollen tubes germinated on the stigma with all three tested factors i.e. viability $(P \leq 0.01)$, germinability $(P \leq$ $0.001)$ and genetic distance $(P \leq 0.01)$ in simple regression analyses and with germinability $(P \leq 0.01)$ and genetic distance $(P \leq 0.05)$ in multiple regression analysis. The strongest correlation was demonstrated for germinability (Table 3). The number of pollen tubes observed in the style was also significantly related to all three factors $(P \leq 0.05, P \leq 0.01$ and $P \leq 0.05$, respectively) in simple regression analysis and to germinability $(P \leq 0.05)$ and genetic distance $(P \leq 0.05)$ in multiple analyses. The correlation observed for the number of pollen tubes in the ovary was weaker, showing significant correlation to germinability and genetic distance (both $P \leq 0.05$ ) in simple and multiple regression analysis. The number of pollen tubes observed in the style and the ovary was strongly related to the numbers of pollen tubes germinating on the stigma (Table 3). Furthermore, when the numbers of pollen tubes observed on stigma were added as explanatory variable in the multiple linear regression the three other explanatory variables were on the border of significance.

\section{Seed morphology, seed set, germination and hybrid plant production}

The morphology of the obtained seeds was evaluated after harvesting. We distinguished three categories of seeds that could be found in Kalanchoë capsules (Figure 6). Category 1 included normal looking seeds that in general were able to produce plants. This category was found in all control crosses, except self-pollination of $K$. gracilipes. For interspecific crosses, category 1 was obtained in crosses of $K$. blossfeldiana cultivars with $K$. nyikae, both directions, and in crosses between $K$. blossfeldiana cultivars with $K$. pubescens and $K$. marnieriana, when wild species were used as pollen donors (Table 2). Category 2 included smaller and wrinkled seeds. This category was found for all crosses where $K$. blossfeldiana cultivars were used as maternal plants, as well as in the crosses where $K$. nyikae was used as maternal plant. Category 3 was seed-like structures with no sign of endosperm and embryo. It was found in all cross-combinations, including inter- and intraspecific crosses. Both category 2 and 3 seeds did not germinate (data not shown).

After harvesting, seed set per capsule was analyzed. The number of obtained normal seeds (category 1 see Figure 6) was generally higher for intraspecific than interspecific crosses (Table 2). In intraspecific hybridization self-pollination of $K$. gracilipes yielded no normal seeds and self-pollination of $K$. blossfeldiana 'Jackie' yielded in average only 5 seeds per flower. Seed set from interspecific crosses was generally low with the exception for the cross K. blossfeldiana '0089A' x K. nyikae (28.2 \pm 4.7 seeds per capsule; mean and S.E.). For other interspecific crosses, 


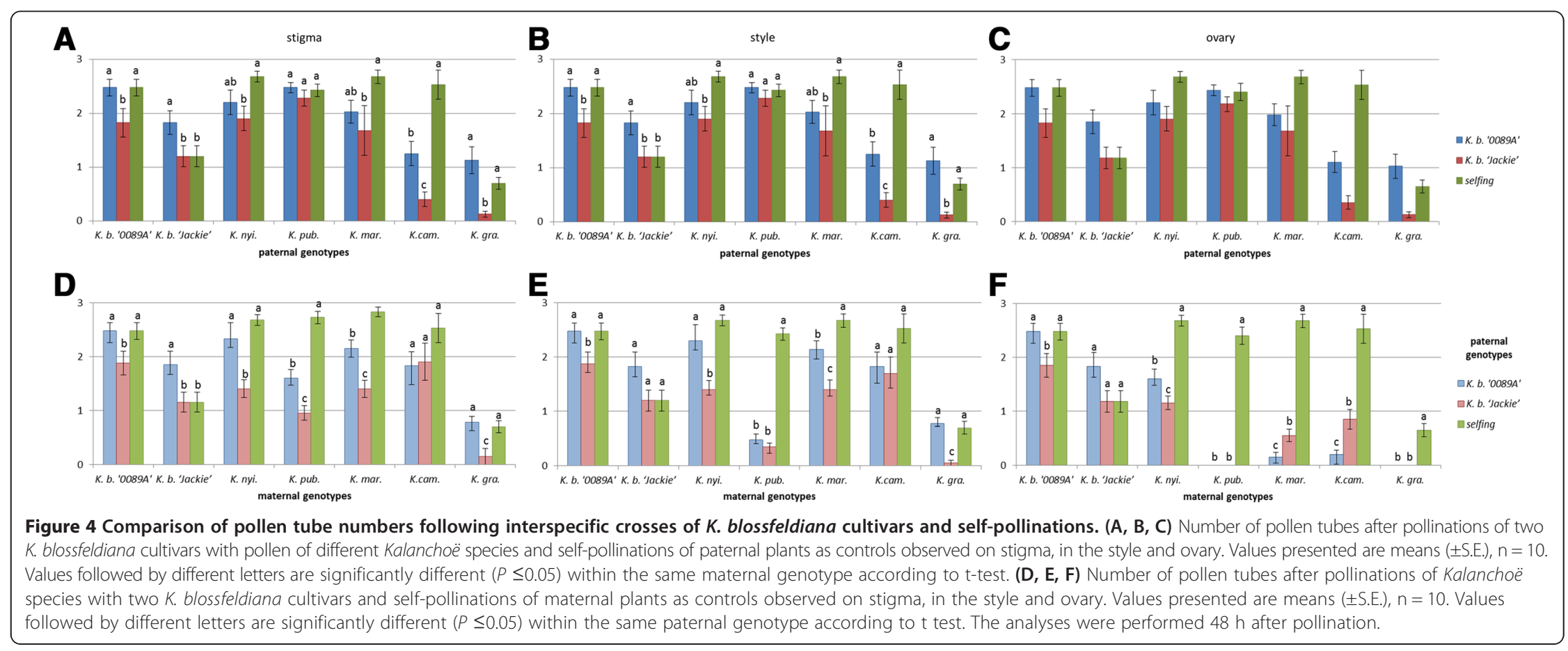



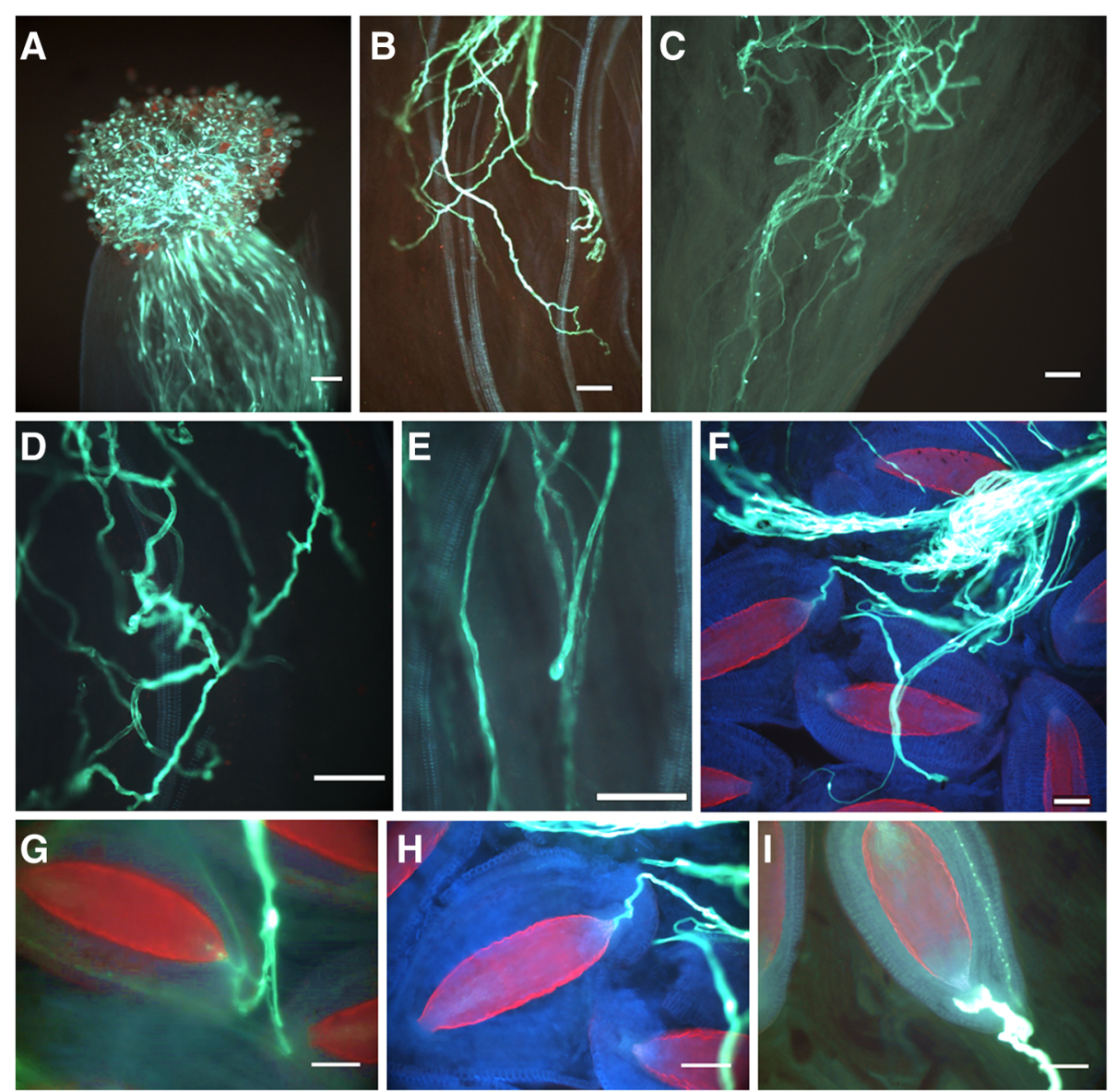

Figure 5 Pollen tube growth and fertilization of Kalanchoë species. (A) Pollen grains of K. pubescens on stigma of K. blossfeldiana 'Jackie' 24 h after pollination (a.p.). (B) Branching of pollen tube, K. campanulata $\times$ K. blossfeldiana '0089A', 24 h a.p. (C) Stopped in growth pollen tubes of $K$. blossfeldiana '0089A' in the style of K. pubescens, 24 h a.p. (D) Spiky pollen tubes, K. campanulata x K. blossfeldiana '0089A', 24 h a.p. (E) Swelling tip of pollen; K. gracilipes $\times$ K. blossfeldiana 'Jackie', 48 h a.p. (F) Pollen tubes of K. pubescens in the ovary of K. blossfeldiana '0089A', 48 h a.p. (G) Pollen tube of $K$. campanulata penetrating the ovule of K. blossfeldiana '0089A', 48 h a.p. (H) Pollen tube of $K$. pubescens penetrating the ovule of $K$. blossfeldiana 'Jackie', 48 h a.p. (I) Pollen tube of K. nyikae penetrated the ovule of K. blossfeldiana '0089A', 24 h a.p. Scale bars: 100 m.

the number of seeds ranged from $0.2 \pm 0.2$ and 0.1 respectively for $K$. nyikae x $K$. blossfeldiana 'Jackie' and $K$. blossfeldiana 'Jackie' x $K$. marnieriana to $6.0 \pm 1.7$ for $K$. blossfeldiana 'Jackie' x K. nyikae.

Germination percentages did not reveal any specificity for intra- or interspecific hybridization. They ranged from $37 \%$ for the cross between $K$. blossfeldiana '0089A' and $K$. marnieriana to $98 \%$ for self-pollinations of $K$. pubescens and $K$. campanulata (Table 2).

Seedling survival was generally higher for intraspecific crosses ranging from 83 to $100 \%$ than for interspecific crosses ranging between 49 and $78 \%$, with the exception of the cross between $K$. blossfeldiana '0089A' and K. marnieriana where seedling survival was $95 \%$ (Table 2).

\section{Hybrid identification}

Morphological hybrid identification was based on the examination of the progeny compared to parental plants.
The hybrids obtained in this study had intermediate phenotype between the parents regarding plant architecture and leaf morphology (Figure 7A) as well as flower morphology (data not shown). Hybrids between smoothleaf cultivars of $K$. blossfeldiana and hairy plants of $K$. pubescens exhibited formation of short hairs on the surface of the leaves. Plants obtained from the crosses among K. blossfeldiana '0089A' and K. marnieriana inherited the purple spots on the leaf margin. The interspecific hybrids of $K$. blossfeldiana with $K$. marnieriana and $K$. pubescens showed more vigorous growth than both parents. Moreover, some genotypes of hybrids among $K$. blossfeldiana '0089A' and K. pubescens exhibited formation of violet spots on the leaf margin and surface that were not observed in any of the parental plants (data not shown).

Based on the morphology of the progeny crosses, $K$. blossfeldiana '0089A' x K. nyikae, K. blossfeldiana 'Jackie' x K. nyikae, K. blossfeldiana '0089A' x K. pubescens and 
Table 3 Relation between number of pollen tubes and pollen viability, germinability and genetic distance

\begin{tabular}{|c|c|c|c|c|c|c|c|c|c|c|c|c|}
\hline \multirow[b]{3}{*}{ Viability } & \multicolumn{4}{|c|}{ Stigma } & \multicolumn{4}{|l|}{ Style } & \multicolumn{4}{|l|}{ Ovary } \\
\hline & \multicolumn{2}{|c|}{ Simple [\%] } & \multicolumn{2}{|c|}{ Multiple [\%] } & \multicolumn{2}{|c|}{ Simple [\%] } & \multicolumn{2}{|c|}{ Multiple [\%] } & \multicolumn{2}{|c|}{ Simple [\%] } & \multicolumn{2}{|c|}{ Multiple [\%] } \\
\hline & $23.4^{1}$ & $* *^{2}$ & & $\mathrm{NS}^{2}$ & 18.1 & $*^{2}$ & & NS & 4.27 & NS & & NS \\
\hline+ stigma ${ }^{3}$ & & & & & $(91.2)$ & $(* * *)$ & & & & & & \\
\hline Germinability & 36.5 & $* * *$ & 51.0 & $* *$ & 28.3 & $* *$ & 40.5 & * & 14.3 & * & 31.9 & * \\
\hline +stigma & & & & & $(91.3)^{4}$ & $(* * *)^{4}$ & & & (66.6) & $(* * *)$ & & \\
\hline Genetic distance & 22.4 & $* *$ & & * & 18.4 & * & & * & 13.8 & * & & * \\
\hline +stigma & & & & & $(91.1)$ & $(* * *)$ & & & $(64.5)$ & $\left({ }^{* * *}\right)$ & & \\
\hline
\end{tabular}

${ }^{1} r^{2}$ value; ${ }^{2} \mathrm{NS},{ }^{* * *},{ }^{* *},{ }^{*}$ indicate non-significant, significant at $P \leq 0.001, P \leq 0.01$ and $P \leq 0.05$, respectively; ${ }^{3}$ stigma as an explanatory variable; ${ }^{4}{ }^{2}$ and significance value for linear model with stigma as an explanatory variable.

The analysis of number of pollen tubes was performed $48 \mathrm{~h}$ after pollination.

K. blossfeldiana 'Jackie' x K. pubescens resulted in $100 \%$ hybrid progeny. For the cross combination $K$. blossfeldiana '0089A' x K. marnieriana and K. nyikae x K. blossfeldiana '0089A' $25.8 \%$ and $9.2 \%$ of the obtained seedlings, respectively, were identified to exhibit hybrid characteristics (Table 2). The rest of the progeny displayed mother-like phenotypes.

AFLP analysis was carried out on 5 randomly selected individuals per cross-combination, which exhibited intermediate characteristics, to confirm hybridity on the molecular level. Band pattern was evaluated and all analyzed plants were verified as hybrids, including the intraspecific cross between $K$. blossfeldiana cultivars. One example of confirmation of hybrid status is presented in Figure 7B.

\section{Discussion}

Many years of breeding with a limited number of species and narrow focus on targeted traits has resulted in restricted gene pool in the current Kalanchoë blossfeldianaderived cultivars [9]. The utilization of wild species has a great potential for genetic improvement of existing breeding material. There are, however, different pre- and postfertilization barriers hindering hybrid development. In our study extensive crosses among different Kalanchoë species and cultivars were performed in order to elucidate the nature of hybridization barriers, to relate them to the genetic distances and to develop novel interspecific hybrids.

\section{Pre-fertilization barriers}

Pollen-pistil interactions are complex series of cellular and molecular interactions occurring between the diploid gynoecium and the haploid male gametophyte [23]. The pistil tissue provides guidance and nutrients that support pollen tube germination and growth; at the same time the pistil ensures a protection of ovules from access of unsuitable pollen [24]. It was suggested that plants with wet stigma surface, as the one occurring in Kalanchoë [25], have indiscriminate adhesion that relies only on liquid surface tension [24]. However, germination and pollen tube growth can be influenced by interactions between pollen and pistil.

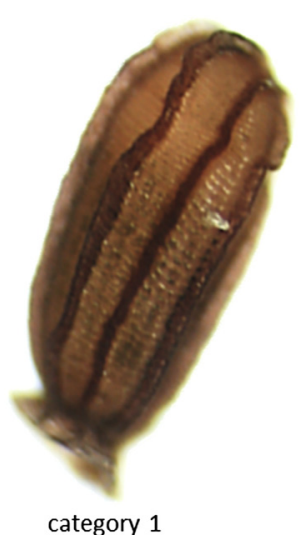

category 1

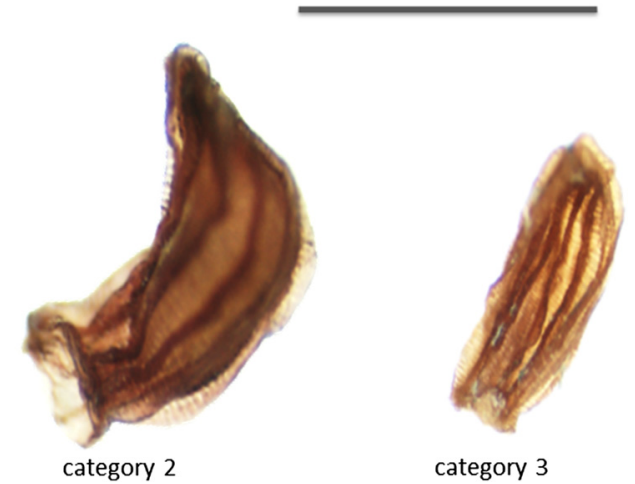

Figure 6 Three types of seed morphology observed after intra- and interspecific crosses in Kalanchoë. Category 1: normal seeds containing fully developed endosperm and embryo, germination; category 2: wrinkled seeds containing not fully developed endosperm, no germination; category 3: seed-like structure with no sign of endosperm and embryo, no germination. Scale bar: $1 \mathrm{~mm}$. 


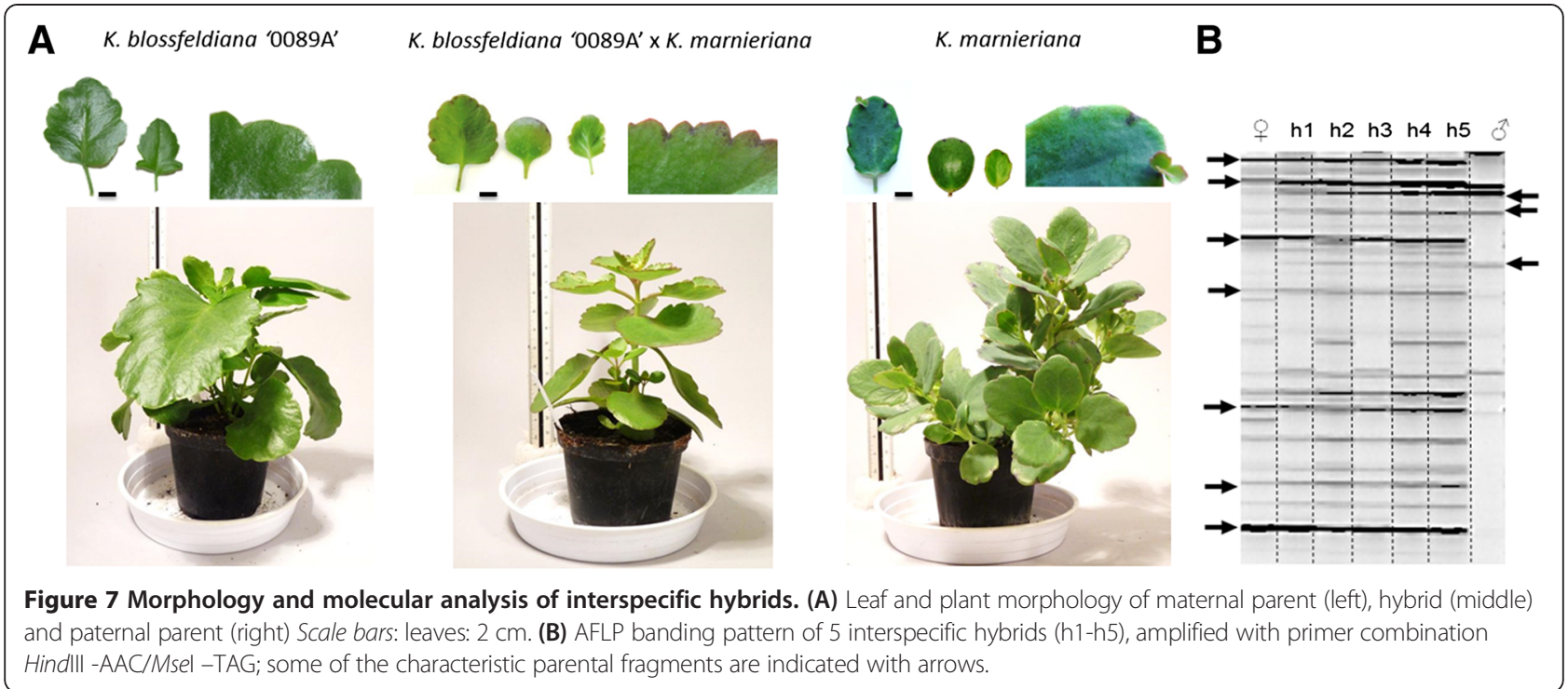

In the present investigation we observed abundant growth of pollen tubes into ovary following selfpollinations of Kalanchoë species. This indicates a lack of the self-incompatibility system in the Kalanchoë genus. Self-pollinations of $K$. blossfeldiana 'Jackie' as well as $K$. gracilipes exhibited a significantly lower numbers of pollen tubes compared to other Kalanchoë species (Figure 4A, green bars). The low viability of the pistilate parent can be a reason for the reduced pollen tubes numbers, as demonstrated in distant crosses of Tulipa species [26].

In our study, examination of pollen germination and growth following interspecific pollination revealed a number of abnormalities. There are different factors in pollen-pistil interactions that influence formation and growth of pollen tubes such as composition of stigmatic exudates [27], water gradient potential in stigma [24], concentration gradients of $\mathrm{Ca}^{2+}$ ions [27], concentration of $\gamma$-aminobutyric acid, lipid molecules and proteins in the style [24]. Thus, species-specific differences regarding these factors can influence the mutual recognition and affect pollen germination and growth.

The quality of pollen used in artificial pollinations is one of the factors strongly affecting the success of pollination. Here, we used two methods to assess pollen quality: acetocarmine staining and in vitro germination test (Figure 1C). The results of germinability were significantly correlated to the numbers of pollen tubes on the stigmas, while viability was less or not significantly correlated (Table 3). These observations agree with the general opinion that in vitro pollen germination analysis is much more accurate for assessment of pollen quality than stain-based methods.

The flowers of Kalanchoë species are characterized by pronounced differences in the length of pistils and styles, especially among species belonging to different sections (Figure 1B). When K. blossfeldiana cultivars were used as paternal plants, the numbers of pollen tubes decreased in styles and ovaries when compared to stigma (Figure 4D-F). This finding agrees with previous results of interspecific hybridization of Kalanchoë, where in intersectional crosses, the hybrids were only obtained, when $K$. blossfeldiana was used as a maternal plants [12]. An analogous unilateral incongruity took place in distant crosses between different Rhododendron species [28]. However, other factors underlying this unilateral incongruity cannot be excluded.

The qualitative analysis of pollen tubes demonstrated atypical growth of pollen tube in wide crosses (Figure 5) suggesting improper interactions between pistil tissues and pollen tubes. Similar aberrations occurred in interspecific crosses in e.g. Rhododendron [29], Dendranthema [30], Abelmoschus [31] and Vigna [32] or the Bromeliaceae family [33]. Thus, this can be an additional evidence for disturbed pollen-pistil interactions occurring among Kalanchoë species.

\section{Post-fertilization barriers}

It is often expected that crosses between individuals possessing the same chromosome numbers are more successful. In our study, interspecific hybrids were obtained following both intra- and interploidy crosses. Consistently, unsuccessful crosses did not exhibit specificity to ploidy level of parental plants. There are other genera in which species show a high level of cross-compatibility between different basic ploidy levels or chromosome numbers. In Salvia [34] and Brassica [35] hybrids from several crosscombinations including plants with different chromosome numbers were obtained. Interploidy hybrids were also obtained e.g. in Chrysanthemum [2] and Dianthus [36]. 
In our studies we observed abnormal wrinkled seeds that occurred with higher frequencies in interspecific crosses than in control pollinations (data not shown) indicating the occurrence of post-fertilization barriers connected to endosperm development. This also agrees with a previous study of interspecific hybridization in the Kalanchoë genus, where hybrids were only obtained following embryo rescue in specific cross-combinations [12].

The abnormal development of endosperm following interspecific crosses is highly similar to that observed in interploidy crosses. The abnormalities of endosperm development can include under- or overproliferation and changes in timing of cellularization. In general, it was postulated that a proper ratio of maternal and paternal genetic material in the endosperm is required for its normal development [37]. A later research on genomic imprinting in plants has suggested that the abnormal development of endosperm may be caused by nonequivalency of imprinted genes. Although the epigenetic modification on parental genes should be complementary within a species, it is possible that the pattern of epigenetic modification and expression of imprinted genes are different in distant species [37].

The genetic differences between cultivars are a plausible explanation for diverse capacity for hybrid production. A similar situation was observed in Petunia [38] and Dianthus [3]. K. blossfeldiana '0089A' was more suitable as hybridization partner than cultivar 'Jackie', both in terms of seed and plant production (Table 2).

\section{The influence of the genetic distance on plant cross- compatibility}

In our study we used AFLPs to determine genetic relations among the Kalanchoë species. The neighbourjoining phenogram obtained from the analysis of 856 markers (Figure 3) revealed a similar clustering compared to previously obtained phenograms from RAPD and ITS data $[39,40]$. All analyses were able to separate the species in the different sections of Kalanchoë. Previous analyses distinguished three main intrageneric clusters that coincide with taxonomic division according to Boiteau [22] that divides the Kalanchoë genus into three sections. In our analysis, the species are separated into two main clusters that coincide with the Bryophyllum and Kalanchoë sections. The species classified into the former section of Kitchingia form a subcluster within Bryophyllum. This situation can be explained by the low number of species included in our analysis. Another reason for the slightly different architecture of the constructed phenogram may be a selection of an outgroup that can influence the position of species in the main clusters.

The genetic distances estimated in this study are relatively high $(0.312-0.801)$ (Table 2$)$. The previous analysis by Gehrig et al. [39] that used RAPD markers reported genetic distances in the same range as reported here. The probable reason for the high level of genetic diversity within the Kalanchoë genus may be a rapid evolutionary development of this taxon [8].

The general theory postulates that difficulties of obtaining interspecific hybrids increase with the phylogenetic distance between parental plants [41]. In the case of plant populations, however, this rule is not necessarily true [42]. In our study, the connection between genetic distances obtained from genotyping using AFLP markers and reproductive isolation exhibited only rough correlation. The obtained results revealed a significant correlation $(P \leq 0.05)$ between the numbers of pollen tubes on the stigma and parental divergence. This may indicate heterospecific differences in composition of stigmatic exudate, or in size and shape of pollen and stigma morphology (data not shown) as it was suggested in Helleborus species [43]. As a consequence, the production of seeds and subsequently plants from interspecific crosses of Kalanchoë was more successful within section than inter-sectional crosses (Table 2), similarly to results obtained for Helleborus [43].

\section{Hybrid characteristics and molecular verification}

The progeny obtained after interspecific pollinations exhibited clear intermediate character for several traits (Figure 7A). The formation of viviparous plants, however, which is a typical trait of the Bryophyllum section, was not observed in the hybrids. This agrees with results of intersectional crosses among $K$. spathulata and $K$. laxiflora, [13,43] and $K$. blossfeldiana and $K$. pubescens [12] where formation of viviparous plants in hybrids was not detected. The findings suggest that this trait is recessive or quantitative [13].

Following the two cross-combinations i.e. K. nyikae $\mathrm{x}$ K. blossfeldiana '0089A' and K. blossfeldiana '0089A' $\times$ K. marnieriana only $9.2 \%$ and $25.8 \%$, respectively, exhibited the intermediate characteristics between both parental plants. The rest of the progeny displayed mother-like phenotypes. A possible explanation for this situation can be an accidental contamination during the pollination. However, unpollinated flowers left as controls on the same maternal plants did not set any seeds. Another possible explanation for mother-like plants is the production of seeds via apomixis $[6,44]$.

\section{Conclusion}

The present work has elucidated details of hybridization barriers occurring during interspecific hybridization within the Kalanchoë genus. Several hybridization barriers have been identified to take place in both the preand the post-fertilization phase. The results suggest that both quality of pollen and style length are strong factors 
influencing the hybridization success. Furthermore, the cross-compatibility between Kalanchoë species is influenced by the genetic background of hybridization partners and genetic distance.

Future breeding efforts should take into consideration the occurrence of unilateral incongruity between Kalanchoë species. Moreover, the abnormal seed development following distant crosses, probably due to endosperm degeneration, suggests utilization of embryo rescue techniques in further attempts to develop new interspecific hybrids.

Two new interspecific hybrids between $K$. nyikae as maternal plants and $K$. blossfeldiana as well as $K$. blossfeldiana and $K$. marnieriana were produced for the first time in our study. Thorough morphological analysis will be performed to evaluate the commercial value of these novel hybrids.

\section{Additional files}

\section{Additional file 1: Scored AFLP marker fragments and levels of polymorphism.}

Additional file 2: Comparison of pollen tube numbers following interspecific crosses of $K$. blossfeldiana cultivars and self-pollinations. (A, B, C). Number of pollen tubes after pollinations of two K. blossfeldiana cultivars with pollen of different Kalanchoë species and self-pollinations of paternal plants as controls observed on stigma, in the style and ovary. Values presented are means $( \pm$ S.E.), $n=10$. Values followed by different letters are significantly different $(P \leq 0.05)$ within the same maternal genotype according to t-test. ( $D, E, F)$ Number of pollen tubes after pollinations of Kalanchoë species with two K. blossfeldiana cultivars and self-pollinations of maternal plants as controls observed on stigma, in the style and ovary. Values presented are means $( \pm S . E),. n=10$. Values followed by different letters are significantly different $(P \leq 0.05)$ within the same paternal genotype according to t-test. The analyses were performed $24 \mathrm{~h}$ after pollination.

\section{Competing interests}

The authors declare that they have no competing interests.

\section{Authors' contributions}

KK contributed to the experimental design, conducted hybridization, microscopic analyses, AFLP analysis, germination test, morphological analysis and was the key person writing the manuscript. HL contributed to experimental design, result discussion and participated in writing of the manuscript. BC contributed to experimental design, result discussion and participated in writing of the manuscript. IS performed statistical analysis of pollen tub numbers and participated in writing of the manuscript. ML contributed to AFLP analysis and data analysis.TW contributed to AFLP analysis and data analysis and revisions of the manuscript. RM contributed to experimental design, result discussion and participated in writing of the manuscript. All authors read and approved the final manuscript.

\section{Acknowledgements}

The authors would like to thank Anita Mortensen, Else Bollerup, Ellen Christensen and Kai Lønne who contributed to the realization of this study, Knud Jepsen A/S, Hinnerup, Denmark, for providing plant material and Dr David Mackenzie for proofreading the manuscript. This project is a part of the innovation consortium "Innovative Plants" funded by the Danish Agency for Science, Technology and Innovation.

\section{Author details}

'Department of Plant and Environmental Sciences, Faculty of Science, University of Copenhagen, Højbakkegård Allé 9-13, DK-2630 Taastrup,
Denmark. ${ }^{2}$ AgroTech A/S, Inst. f. Agri Technology and Food Innovation, Højbakkegård Allé 21, DK-2630 Taastrup, Denmark. ${ }^{3}$ Department of Mathematical Sciences, Faculty of Science, University of Copenhagen, Universitetsparken 5, DK-2100 København $\varnothing$, Denmark. ${ }^{4}$ Institute for Plant Genetics, Leibniz Universität Hannover, Herrenhaeuser Str. 2, D-30419 Hannover, Germany. ${ }^{5}$ Institute of Horticultural Production Systems, Leibniz Universität Hannover, Herrenhaeuser Str. 2, D-30419 Hannover, Germany.

Received: 7 August 2014 Accepted: 22 December 2014

Published online: 21 January 2015

\section{References}

1. De Cock K, Scariot V, Leus L, Riek J, Van Huylenbroeck J. Understanding genetic relationships of wild and cultivated roses and the use of species in breeding. CAB Reviews. 2007;2(052):10.

2. Cheng $X$ et al. Creating novel chrysanthemum germplasm via interspecific hybridization and backcrossing. Euphytica. 2010;177(1):45-53.

3. Nimura M, Kato J, Mii M, Morioka K. Unilateral compatibility and genotypic difference in crossability in interspecific hybridization between Dianthus caryophyllus L. and Dianthus japonicus Thunb. Theor Appl Genet. 2003;106(7):1164-70.

4. Van Tuyl J, Van Dijken A, Chi H, Lim K-B, Villemoes S, Van Kronenburg B. Breakthroughs in interspecific hybridization of lily. Acta Hort. 1998;508:83-90.

5. Eeckhaut T, De Keyser E, Van Huylenbroeck J, De Riek J, Van Bockstaele E. Application of embryo rescue after interspecific crosses in the genus Rhododendron. PCTOC. 2007:89(1):29-35.

6. Morgan ER, Timmerman-Vaughan GM, Conner AJ, Griffin WB, Pickering R. Plant Interspecific Hybridization: outcomes and issues at the intersection species. In: Plant Breeding Reviews. New York: John Wiley \& Sons, Inc; 2010. p. $161-220$.

7. Rieseberg LH, Carney SE. Plant hybridization. New Phytol. 1998;140:599-624.

8. Descoings B. Kalanchoe. In: Eggli U, Hartmann HEK, editors. Illustrated handbook of succulent plants Crassulaceae. New York: Springer Verlag; 2003. p. 143-81.

9. van Voorst A, Arends JC. The origin and chromosome numbers of cultivars of Kalanchoe blossfeldiana Von Poelln.: Their history and evolution. Euphytica. 1982;31:573-84.

10. Floradania Marketing. Top 10 over danske kulturer 2012 [http://floradania.dk/ fileadmin/s3/pdf/Branchenyt/Topliste/Top_10_over_kulturer___Danmark_2012.pdf]

11. Floraholland. Facts and figures 2012 [http://www.floraholland.com/media/ 1525240/KengetallenEN2012.pdf]

12. Izumikawa Y, Nakamura I, Mii M. Interspecific hybridization between Kalanchoe blossfeldiana and several wild Kalanchoe species with ornamental value. Acta Hort. 2008;743:59-66.

13. Izumikawa Y, Takei S, Nakamura I, Mii M. Production and characterization of inter-sectional hybrids between Kalanchoe spathulata and K. laxiflora ( = Bryophyllum crenatum). Euphytica. 2007;163(1):123-30.

14. Lütken H, Laura M, Borghi C, Orgaard M, Allavena A, Rasmussen SK. Expression of KxhKN4 and KxhKN5 genes in Kalanchoe blossfeldiana 'Molly' results in novel compact plant phenotypes: towards a cisgenesis alternative to growth retardants. Plant Cell Rep. 2011;30(12):2267-79.

15. Doyle JJ. A rapid DNA isolation procedure for small quantities of fresh leaf tissue. Phytochem Bull. 1987;19:11-5.

16. Vos $\mathrm{P}$, Hogers $R$, Bleeker $M$, Reijans $M$, van de Lee $T$, Hornes $M$, et al. AFLP: a new technique for DNA fingerprinting. Nucleic Acids Res. 1995;23(21):4407-14.

17. Saitou N, Nei M. The neighbor-joining method: a new method for reconstructing phylogenetic trees. Mol Biol Evol. 1987;4(4):406-25.

18. Felsenstein J. Confidence limits on phylogenies: an approach using the bootstrap. Evolution. 1985;39(4):783-91.

19. Schlueter PM, Harris SA. Analysis of multilocus fingerprinting data sets containing missing data. Mol Ecol Notes. 2006;6(2):569-72.

20. Singh RJ. Plant cytogenetics. Boca Raton: CRC press; 2010

21. Taylor R. Germination of cotton (Gossypium hirsutum L.) pollen on an artificial medium. Crop Sci. 1972;12:243-4.

22. Boiteau P, Allorge-Boiteau L. Kalanchoe (Crassulacées) de Madagascar: systématique, écophysiologie et phytochimie. Paris: Editions Karthala; 1995.

23. Sanchez AM, Bosch M, Bots M, Nieuwland J, Feron R, Mariani C. Pistil factors controlling pollination. Plant Cell Online. 2004;16 suppl 1:98-106.

24. Swanson R, Edlund AF, Preuss D. Species specificity in pollen-pistil interactions. Annu Rev Genet. 2004;38(1):793-818. 
25. Traoré L, Kuligowska K, Lütken H, Müller R. Stigma development and receptivity of two Kalanchoë blossfeldiana cultivars. Acta Physiol Plant. 2014;36(7):1763-9.

26. Creij MGMV, Kerckhoffs DMFJ, Tuyl JMV. Interspecific crosses in the genus Tulipa L.: identification of pre-fertilization barriers. Sex Plant Reprod. 1997;10(2):116-23.

27. Gao X-Q, Zhu D, Zhang X. Stigma factors regulating self-compatible pollination. Front Biol. 2010;5(2):156-63.

28. Williams EG, Rouse JL. Relationships of pollen size, pistil length and pollen tube growth rates in Rhododendron and their influence on hybridization. Sex Plant Reprod. 1990;3(1):7-17.

29. Williams EG, Knox BR, Rouse JL. Pollination sub-systems distinguished by pollen tube arrest after incompatible interspecific crosses in Rhododendron (Ericaceae). J Cell Sci. 1982;53(1):255-77.

30. Sun C-Q, Chen F-D, Teng N-J, Liu Z-L, Fang W-M, Hou X-L. Factors affecting seed set in the crosses between Dendranthema grandiflorum (Ramat.) Kitamura and its wild species. Euphytica. 2010;171(2):181-92.

31. Abdullah Yousuf Akhond M, Abul Hossain Molla M, Obaidul Islam M, Ali M. Cross compatibility between Abelmoschus esculentus and A. moschatus. Euphytica. 2000;114(3):175-80.

32. Barone A, Del Giudice A, Ng N. Barriers to interspecific hybridization between Vigna unguiculata and Vigna vexillata. Sex Plant Reprod. 1992;5(3):195-200.

33. Vervaeke I, Parton E, Maene L, Deroose R, De Proft MP. Prefertilization barriers between different Bromeliaceae. Euphytica. 2001;118(1):91-7.

34. Tychonievich J, Warner R. Interspecific Crossability of Selected Salvia Species and Potential Use for Crop Improvement. J Amer Soc Hort Sci. 2011;136:41-7.

35. FitzJohn R, Armstrong T, Newstrom-Lloyd L, Wilton A, Cochrane M. Hybridisation within Brassica and allied genera: evaluation of potential for transgene escape. Euphytica. 2007;158(1-2):209-30.

36. Gatt MK, Hammett KRW, Markham KR, Murray BG. Yellow pinks: interspecific hybridization between Dianthus plumarius and related species with yellow flowers. Scientia Hort. 1998;77(3-4):207-18.

37. Kinoshita T. Reproductive barrier and genomic imprinting in the endosperm of flowering plants. Genes Genet Syst. 2007;82(3):177-86.

38. Warner RM, Walworth AE. Quantitative inheritance of crop timing traits in interspecific hybrid petunia populations and interactions with crop quality parameters. J Hered. 2010;101(3):308-16.

39. Gehrig $H$, Rosicke $H$, Kluge M. Detection of DNA polymorphisms in the genus Kalanchoe by RAPD-PCR fingerprint and its relationships to infrageneric taxonomic position and ecophysiological photosynthetic behaviour of the species. Plant Sci. 1997;125:41-52.

40. Gehrig H, Gaußmann O, Marx H, Schwarzott D, Kluge M. Molecular phylogeny of the genus Kalanchoe (Crassulaceae) inferred from nucleotide sequences of the ITS-1 and ITS-2 regions. Plant Sci. 2001;160(827-836):827-35.

41. Sharma HC. How wide can a wide cross be? Euphytica. 1995;82:43-64.

42. Moyle LC, Olson MS, Tiffin P. Patterns of reproductive isolation in three angiosperm genera. Evolution. 2004;58(6):1195-208.

43. Meiners J, Winkelmann T. Evaluation of reproductive barriers and realisation of interspecific hybridisations depending on genetic distances between species in the genus Helleborus. Plant Biol. 2012;14(4):576-85.

44. Koltunow AM. Apomixis: embryo sacs and embryos formed without meiosis or fertilization in ovules. Plant Cell. 1993;5(10):1425.

\section{Submit your next manuscript to BioMed Central and take full advantage of:}

- Convenient online submission

- Thorough peer review

- No space constraints or color figure charges

- Immediate publication on acceptance

- Inclusion in PubMed, CAS, Scopus and Google Scholar

- Research which is freely available for redistribution

Submit your manuscript at www.biomedcentral.com/submit 